\title{
Comportamento Verbal e Correspondência no Filme Rashômon
}

Verbal Behavior and Correspondence in the Film Rashomon

Comportamiento Verbal y Correspondencia em la Película Rashomon

\author{
Julio C. de Rose'
}

[1] Universidade Federal de São Carlos e Instituto Nacional de Ciência e Tecnologia sobre Comportamento, Cognição e Ensino I Título abreviado: Comportamento Verbal e Correspondência no Filme Rashômon | | Endereço para correspondência: | Email: | doi: 10.18761/PAC.2018.n2.06

Resumo: O filme Rashômon, dirigido por Akira Kurosawa e lançado em 1950, costuma estar presente em todas as listas de melhores filmes de todos os tempos elaboradas por conhecedores de cinema. Vários personagens do filme narram o mesmo evento, mas os testemunhos são completamente diferentes. Neste artigo tratamos os personagens como se fossem pessoas reais. Seus relatos são, assim, tratados como se fossem comportamento verbal de pessoas reais, sujeitas a contingências reais. Podemos nos perguntar, então, quais seriam as variáveis responsáveis pelas discrepâncias nas histórias. Neste caso, é possível fazer conjecturas e hipóteses, mas falta um elemento essencial para aferir nossas hipóteses: como só poderíamos saber o que aconteceu com base no relato das testemunhas, e como não há confirmação independente dos detalhes da história, não podemos avaliar o quanto as descrições estão de fato sob controle dos presumidos acontecimentos e o quanto estariam sob controle de variáveis que podem distorcer a acurácia de um relato.

Palavras-chave: Comportamento Verbal; Correspondência; mentira; Rashômon; Kurosawa 


\begin{abstract}
Rashomon, the movie directed by Akira Kurosawa (1950), is virtually in all lists of best all time movies made by cinema connoisseurs. Several characters in the movie report the same event but the accounts are completely different. In this article we treat the characters as if they were real persons. Their reports are, therefore, treated as if they were real verbal behavior, controlled by real contingencies. We may ask, therefore, what variables were responsible for the discrepancies in the stories. In this case it is possible to raise plausible hypotheses, but a crucial element to evaluate such hypotheses is missing: we could know what happened only based on the report by the witnesses. As there is no independent confirmation of the story's details, we cannot estimate to what extent the descriptions were indeed under control of the reported facts and to what extent they were controlled by variables that could distort the testimonies.
\end{abstract}

Keywords: Verbal Behavior; Correspondence; Lying; Rashomon; Kurosawa

Resumen: La película Rashomon, dirigida por Akira Kurosawa y lanzada en 1950, suele estar presente en todas las listas de las mejores películas de todos los tiempos elaboradas por conocedores de cine. Varios personajes de la película narran el mismo evento, pero los testimonios son completamente diferentes. En este artículo tratamos a los personajes como si fueran personas reales. Sus relatos se tratan como si fueran comportamiento verbal de personas reales, sujetas a contingencias reales. Podemos preguntarse, entonces, cuáles serían las variables responsables de las discrepancias en las historias. En este caso, es posible hacer conjeturas e hipótesis, pero falta un elemento esencial para medir nuestras hipótesis: como sólo podríamos saber lo que ocurrió sobre la base del relato de los testigos, y como no hay confirmación independiente de los detalles de la historia, no podemos evaluar cuánto las descripciones están de hecho bajo control de los presuntos acontecimientos y cuánto estarían bajo control de variables que pueden distorsionar la exactitud de un relato.

Palabras-clave: Compartamiento Verbal; Correspondencia; Mentira; Rashomon; Kurosawa

Nota: Muitos colegas e alunos contribuíram para este trabalho, com revisões críticas das versões preliminares e valiosas sugestões. Com o risco de estar esquecendo alguém, agradeço a Ana Arantes, Josiane Donadeli, Júlia Freitas, Mariéle Cortez, Marlon de Oliveira, Melina Vaz e Táhcita Mizael pelas preciosas sugestões. Também, muitas vezes discuti este filme com turmas da graduação em psicologia da UFSCar e os comentários de muitos alunos contribuíram para a minha visão sobre o filme. Lembro particularmente das considerações do Paulo Bertoni sobre a esgrima japonesa. Para preparação deste manuscrito eu contei com apoio do Instituto Nacional de Ciência e Tecnologia sobre Comportamento, Cognição e Ensino (INCT/ECCE, Processos CNPq 465686/2014-1 e FAPESP 2014/50909-8) e também contei com bolsa de produtividade em pesquisa do CNPq. Agradeço à Coordenadora do INCT/ECCE, Professora Deisy de Souza, pelo apoio constante. 
As pessoas tendem a confiar bastante no relato de quem presenciou um acontecimento. Os psicólogos sabem, no entanto, que os testemunhos frequentemente são falíveis. Distorções de memória são comuns. Elizabeth Loftus, em um famoso TED Talk ${ }^{1}$, compara a memória a uma página da Wikipedia, onde novas experiências podem alterar o conteúdo que está escrito. Por essa razão, pessoas de boa fé muitas vezes fazem relatos que não correspondem aos fatos, às vezes até sob juramento diante de um tribunal. Há outras razões pelas quais um relato pode ser inverídico ou distorcido. Como observou Glenn (1993), as pessoas podem ter observado mal e por isso podem enganar-se quando relatam de boa fé. Além disso, as pessoas podem mentir, distorcer intencionalmente o relato de eventos.

Pesquisas indicam que mentiras são frequentes em interações diárias (De Paulo \& Kashy, 1998; Feldman, Forrest \& Happ, 2002; Newton, Reddy \& Bull, 2000; Talwar \& Lee, 2008). Feldman et al., por exemplo, registraram conversas de 10 minutos entre duas pessoas desconhecidas que não sabiam que estavam sendo gravadas (sim, ninguém ignora que pesquisadores de psicologia também mentem para os participantes de seus experimentos!), e estimaram, com base em depoimentos posteriores dos participantes, uma frequência média de 3 mentiras por pessoa em 10 minutos de conversa, com alguns participantes chegando a mais de 10 mentiras.

Particularmente, a análise do comportamento tem contribuído para revelar contingências ambientais que afetam a probabilidade de relatos verídicos (Alves, 2018; Antunes \& Medeiros, 2016; Cortez, de Rose \& Miguel, 2014; Cortez, de Rose \& Montagnoli, 2013; Cortez, Miguel \& de Rose, 2017; Domeniconi, de Rose \& Perez, 2014; Lanza, Starr \& Skinner, 1982; Glenn, 1993; Medeiros, Oliveira \& Silva, 2013; Oliveira, Cortez \& de Rose, 2016; Ribeiro, 1989; Skinner, 1957). Todos estes estudos da psicologia e da análise do comportamento nos levam a tomar testemunhos com muita cautela: sujeitos a falhas de observação, distorções de memória e mentiras, os relatos das pessoas sobre eventos que presenciaram ou nos quais se envolveram podem ser pouco confiáveis.

1 Disponível em https://www.ted.com/talks/elizabeth_loftus_the_fiction_of_memory?language=pt-br
A inconfiabilidade dos relatos é abordada dramaticamente em um filme famoso, Rashômon, de 1950, dirigido pelo cineasta japonês Akira Kurosawa (1910-1998). O objetivo deste artigo é fazer uma análise deste filme e dos contos em que ele é baseado, de autoria do escritor japonês Ryûnosuke Akutagawa (1892-1927).

A literatura, incluindo o teatro e, por extensão, o cinema, podem ser fontes interessantes para complementar o conhecimento científico sobre comportamento, ou até mesmo para promover o avanço desse conhecimento. Obras literárias ou cinematográficas, embora geralmente tratem do comportamento de personagens fictícios, podem demonstrar um refinado conhecimento do comportamento humano, de modo que a atuação dos personagens pode ser analisada em seus processos comportamentais de forma análoga ao comportamento de pessoas reais (e.g., Arantes \& de Rose, 2009).

O recurso a fontes literárias (i.e., romances, contos, novelas, poesia) foi abundantemente utilizado, por exemplo, por B. F. Skinner, em sua interpretação do comportamento verbal (Skinner, 1957). No seu livro Verbal Behavior, que buscava abarcar os mais diversos fenômenos e processos relativos ao comportamento verbal, este autor, em virtude da relativa escassez de pesquisa científica que atendesse seus critérios, fez uso frequente de trechos ou episódios extraídos de fontes literárias. Ele tratou trechos literários como se fossem descrições acuradas de comportamentos de pessoas reais, que ilustravam os processos comportamentais tratados no livro. Em nosso modesto trabalho, faremos uma trajetória inversa: vamos partir de um trabalho literário/cinematográfico particular e buscar o que ele pode iluminar a respeito de uma questão relativa ao comportamento verbal, o testemunho não confiável.

\section{Rashômon: o filme e os contos}

Rashômon é um filme de 1950, dirigido pelo cineasta japonês Akira Kurosawa (1910-1998). Foi o primeiro filme japonês a fazer sucesso no Ocidente, tendo sido premiado no Festival de Veneza em 1951 e também premiado com um Oscar honorário de melhor filme estrangeiro, em 1952, antes mesmo de ser es- 
tabelecida a premiação anual para esta categoria. É provável que um espectador médio nos dias de hoje, principalmente se for jovem, considere Rashômon um insuportável "filme-cabeça". É filmado em preto-e-branco, sem efeitos especiais e narra uma história complexa e ambígua, com atores japoneses hoje desconhecidos, atuando de forma que para o espectador atual pode beirar o bizarro. Para os especialistas e conhecedores de cinema, no entanto, Rashômon é um filme icônico, sempre presente nas listas de "melhores de todos os tempos", tendo influenciado diretores famosos como Fellini, Scorsese, Spielberg, e muitos outros. A fama de Rashômon extrapolou a arte cinematográfica, estendendo-se à filosofia e as ciências humanas: o Efeito Rashômon se refere ao questionamento sobre a existência ou possibilidade de conhecimento da verdade quando são cotejadas perspectivas diferentes e incompatíveis sobre um mesmo fato (e.g., Anderer, 2016; Clotter, 2013; Heider, 1988; Roth \& Mehta, 2002)

O filme é baseado em dois contos do escritor japonês Ryûnosuke Akutagawa (1892-1927)², com alterações introduzidas pelos roteiristas, do filme, Kurosawa e Shinobu Hashimoto. Vamos tratar inicialmente dos contos e depois das alterações efetuadas no filme.

A ação do filme segue de perto um conto de Akutagawa, Dentro do Bosque (1921), que se passa em Quioto, antiga capital do Japão, em algum momento da Era Heyan (794-1192). O conto se apresenta como a transcrição de uma série de depoimentos dados a um tribunal, sobre um crime que envolveu o estupro de uma mulher e a morte de seu marido, um samurai. Diversas testemunhas apresentam sua versão dos fatos que presenciaram, especialmente as quatro personagens mais diretamente envolvidas: um lenhador que encontrou o corpo, o conhecido bandido Tajômaru, a mulher e o próprio samurai morto, que fala por meio de uma médium. No filme, as ações aparecem narradas em flashback. Vejamos o essencial dos depoimentos,

2 Para redigir este texto utilizei a coletânea Rashômon e Outros Contos, em edição revista de 2011, da Editora Hedra, de São Paulo, com tradução de Madalena Hashimoto Cordaro e Junko Ota. A fonte das informações sobre o autor, sobre os contos e sobre Quioto na Era Meyo foi a introdução a esta coletânea, de autoria de Madalena Hashimoto Cordaro. no conto, para tratar depois das alterações que foram feitas no filme:

O lenhador encontrou o cadáver do samurai numa clareira em um bosque situado a alguma distância da estrada, onde ele tinha ido cortar lenha. Ele diz que viu um ferimento profundo por espada e que havia apenas uma corda e um pente nas proximidades. Em seguida, um monge budista conta ter visto o casal na estrada, o samurai a pé, portando espada, arco e flechas, com a mulher a cavalo, tendo o rosto oculto por um véu. $\mathrm{O}$ depoimento seguinte é do policial que encontrou o bandido Tajômaru gemendo de dor após ter, aparentemente, caído do cavalo. O policial acrescenta que, dos bandidos da região, este é o que mais persegue as mulheres. A sogra do samurai, em seguida, informa que a filha tinha 19 anos e o marido 26, e que a personalidade da filha era tão forte quanto a de qualquer homem ${ }^{3}$.

Segue-se então o depoimento de Tajômaru. Ele disse que viu o casal na estrada e decidiu possuir a mulher, se possível poupando o marido, mas matando-o, se necessário. Ele abordou o casal e atraiu o marido para uma clareira em um bosque à margem da estrada, onde disse ter enterrado objetos valiosos. Ao ouvir que o tesouro estava enterrado ali, o samurai se precipitou para o local indicado, dando as costas a Tajômaru. Este o atacou, dominou, desarmou e amarrou, enchendo a boca do homem de folhas para que não falasse ou gritasse. Foi então chamar a mulher, que havia ficado à distância, dizendo a ela que o marido passava mal, mas quando ela viu o marido amarrado, tirou um punhal das vestes e atacou ferozmente o bandido, com golpes dos quais ele teve dificuldade de se esquivar. Ele conseguiu dominar a mulher e a possuiu ali, em frente ao marido. Quando ia fugindo do bosque, a mulher o agarrou e disse que não suportaria viver desonrada diante de dois homens e que um deles deveria morrer: ela ficaria com o que vencesse a luta. Tajômaru diz que desamarrou o homem para lutarem de igual para igual. Ele teria sido o adversário mais difícil que Tajômaru enfrentou, cruzando espadas com ele 23 vezes, sendo que

3 A sogra do samurai informou também que o nome da jovem era Masago e seu marido se chamava Takehiro Kanazawano. Esse detalhe é curioso, porque no filme o único personagem cujo nome é revelado é o bandido. 
nenhum oponente anterior havia chegado a mais de 20 vezes. Quando ele se voltou para a mulher, ela tinha desaparecido e então o bandido foi embora também, levando o cavalo, a espada, o arco e as flechas do morto. Note-se aqui que o bandido não menciona o punhal. No filme, este ponto adquirirá uma importância central.

A mulher depôs em seguida. Disse que, após ser estuprada, percebeu em seu marido um olhar gélido de desprezo. Ao voltar a si de um desmaio, viu o mesmo olhar de desprezo, no qual percebeu também ódio. Disse então ao marido que não poderia mais viver com ele, que iria se suicidar e que o marido, que testemunhou sua desonra, também deveria morrer. Cravou então o punhal no peito do marido, mas depois não teve coragem de se matar.

Seguiu-se o depoimento do morto que, como dito antes, foi incorporado por uma médium. Ele disse que o bandido, após violentar a mulher, habilmente convenceu-a a abandonar o marido e ir embora com ele. Mas a mulher, antes de ir, pediu ao bandido que matasse o marido. $\mathrm{O}$ bandido, aparentemente chocado com esta proposta, hesitou um instante e depois derrubou a mulher e perguntou ao marido o que fazer com ela: mata-la ou deixa-la ir. O marido (que diz ter perdoado o bandido quando ele disse estas palavras) hesitou um instante e enquanto isso a mulher conseguiu fugir. $\mathrm{O}$ bandido rompeu um ponto das cordas que amarravam o samurai e fugiu, levando a espada, o arco e as flechas. Quando conseguiu se soltar, o samurai encontrou o punhal da mulher que havia ficado no chão e cravou-o no peito. Antes de morrer, quando a escuridão já o envolvia, sentiu alguém se aproximar e arrancar o punhal do seu peito, mas não conseguiu ver quem era.

Não podemos tratar do filme sem antes mencionar o outro conto de Akutagawa, intitulado Rashômon. Este era o nome do portal da cidade de Quioto na Era Heyan. O sombrio conto de Akutagawa nos mostra um panorama desolador. "Nos últimos dois ou três anos, Quioto sofrera seguidas calamidades: terremotos, redemoinhos, incêndios e fome... tirando partido do abandono em que o Portal se encontrava, raposas e texugos começaram a se abrigar ali. E também ladrões. Até que, afinal, passado um tempo, virou hábito abandonar, no Rashômon, cadáveres não reclama- dos. Por isso, quando a luz do dia não podia mais ser vista, era tamanho o pavor que ninguém mais ousava se aproximar". Neste conto, um servo que havia sido dispensado por seu senhor abriga-se no Rashômon de uma chuva torrencial e dá-se conta de que sua única perspectiva de sobrevivência seria tornar-se ladrão. A sórdida história envolvendo o servo no interior do Rashômon não é relevante para o filme. Kurosawa utiliza deste conto apenas o título para o filme, o Portal como abrigo numa chuva torrencial e o estado de decadência da região, que pode ser entrevisto nas conversas dos personagens do filme.

Como dito antes, o filme segue de perto a ação do conto Dentro do Bosque, mas introduz algumas modificações. No filme, o lenhador que encontrou o corpo, poucos dias depois abriga-se da chuva no Rashômon ${ }^{4}$ e lá conversa com um "padre" 5 e com um outro indivíduo, não identificado, a quem vou me referir como um "plebeu". O lenhador e o padre rememoram os perturbadores depoimentos a respeito do crime envolvendo o samurai e sua mulher. A ação narrada nos depoimentos aparece em flashback. Há alguns acréscimos e mudanças importantes no depoimento de Tajômaru. Ele come-

4 Anderer (2016) informa que a construção do portal levou 25 dias e consumiu praticamente todo o orçamento do filme. Só no telhado foram usadas 40 mil telhas. Para acentuar o cenário de decadência o portal aparece em ruínas, com o seu lado direito praticamente desabando. Como lembra Anderer, Tóquio tinha sido devastada pelos bombardeios do final da Segunda Guerra Mundial, a segunda devastação que a cidade sofreu em poucas décadas, pois já tinha sido praticamente destruída pelo Grande Terremoto de Kantô, em 1923. Kurosawa esteve presente nas duas destruições de sua cidade, enquanto Akutagawa presenciou apenas a primeira. A decadência da Quioto do conto de Akutagawa e do filme de Kurosawa corresponde, portanto, à ruína de Tóquio e de todo o Japão na época em que o filme foi feito, pouco após o final da Guerra.

5 O "padre" corresponde ao monge budista do conto. A transformação do monge do conto em padre, no filme, é curiosa. Padres são associados com o catolicismo, religião pouco comum no Japão, e inexistente na época em que o filme se passa. Minha desconfiança inicial era de um erro de tradução nas legendas do filme em português, algo nada incomum. No entanto, li várias críticas e resenhas de Rashômon em inglês, e em todas elas o personagem é descrito como um "padre". Não encontrei nenhuma explicação de como um padre aparece no Japão muitos séculos antes da introdução do catolicismo no país. 
ça negando que tenha caído do cavalo. Para o fato de ter sido encontrado gemendo no chão, ele dá a improvável explicação de ter bebido água de uma fonte que devia estar contaminada. Na descrição do estupro, vemos que quando Tajômaru domina a mulher e a beija, esta gradualmente cessa a resistência, solta o punhal (que fica cravado no chão) e passa a retribuir o beijo: Tajômaru sugere, assim, que a mulher teria consentido na relação, que na versão dele, portanto, teria sido mais uma sedução do que um estupro. No conto, como mencionado antes, Tajômaru não esclarece o que teria acontecido com o punhal, mas no filme ele termina o depoimento informando que se esqueceu de levar o punhal, e que isto teria sido seu maior erro, pois o punhal deveria ser muito valioso.

O depoimento da mulher, no filme, não afirma tão explicitamente quanto no conto que ela matou o marido. Vemo-la segurando o punhal apontado para o marido e depois ela desmaia e ao voltar a si encontra o marido morto. Quanto ao depoimento do morto, no filme, ele é bem semelhante ao do conto.

$\mathrm{O}$ que teria acontecido então com o punhal? O filme acrescenta uma explicação deste ponto: no Portal, conversando com o padre e o plebeu, o lenhador admite que mentiu e reconta a história. Ele teria chegado à cena logo após o estupro e, escondido, vê o bandido virtualmente rastejando aos pés da mulher, prometendo regenerar-se caso ela se torne sua esposa. A mulher diz que não cabe a ela decidir e o bandido então liberta o samurai, mas este diz que se recusa a arriscar a vida por aquela mulher. Instados principalmente pela mulher, os dois começam uma luta na qual se mostram apavorados e de inabilidade grotesca. Tajômaru erra um golpe e sua espada crava-se no chão. Ele tenta retirá-la, mas ela enterrou-se profundamente. $\mathrm{O}$ samurai o ataca e ele é obrigado a afastar-se, rastejando, e o samurai erra vários golpes contra o inimigo desarmado. Finalmente, Tajômaru consegue retomar sua espada e termina por desarmar e encurralar o samurai. Este implora para não ser morto, mas o bandido mata-o com um golpe de espada. Durante a luta, a mulher fugiu. O bandido vai embora com a espada, o cavalo, o arco e as flechas do samurai. A câmara mostra o solo, onde não se vê mais o punhal cravado.
O lenhador poderia, em princípio, ser tomado como uma testemunha mais objetiva que, ao contrário dos outros envolvidos, não teria interesses específicos que o levassem a mentir. De fato, os depoimentos do bandido, da mulher e do samurai parecem enviesados de modo a cada um deles justificar seu comportamento e apresenta-lo como o mais honrado possível diante das circunstâncias. $\mathrm{O}$ bandido teria matado o samurai numa luta heroica e honesta; o comportamento da mulher poderia ser justificado pelo desprezo do marido; o samurai alega ter se suicidado, um comportamento honroso na cultura japonesa, e nega a vergonha de ter sido derrotado pelo bandido em uma luta de igual para igual. Mas de acordo com o testemunho do lenhador aos seus interlocutores no portal, o comportamento de todos os três foi desprezível.

Vários contos de Akutagawa mostram homens divididos entre a busca dos seus interesses (os reforçadores pessoais) e uma postura mais altruísta (o "bem para os outros", nas palavras de Skinner, 1971), e com o frequente predomínio dos motivos egoístas. O filme, até aqui, parece endossar esta visão sombria do homem, visto que o comportamento verbal ou não verbal de todos os personagens, inclusive o lenhador, teria sido egoísta, mesquinho e desprezível, buscando atender apenas os próprios interesses. Mas Kurosawa inseriu, um pouco artificialmente, um final que se afasta desta visão pessimista e que não é relevante para a argumentação deste artigo $^{6}$.

$6 \mathrm{Na}$ cena final do filme, ouve-se um choro de criança e os três interlocutores descobrem um bebê abandonado no Rashômon, dentro de um cesto. O plebeu pega de dentro do cesto, para si, dois objetos de valor, um quimono e um amuleto. Ao ser repreendido pelo lenhador, o plebeu diz que todos os homens são egoístas e que o lenhador era um bandido repreendendo outro bandido, pois também havia roubado o valioso punhal que encontrou na cena do crime. A chuva tinha parado e o plebeu vai embora levando o quimono e o amuleto. O lenhador pega o bebê e o padre não quer deixar a criança com aquele homem que também havia se comportado de modo indigno. Mas o lenhador diz que pode cuidar do bebê porque já tem seis filhos e poderia arcar com mais um. O padre havia se enganado em relação ao lenhador e o comportamento dele, apesar de ter roubado o punhal, pode ser generoso e desinteressado. O lenhador vai embora com o bebê nos braços e o padre agradece a ele por ter recuperado sua fé na humanidade. 


\section{Uma análise comportamental de Rashômon}

Relatar é comportamento verbal. Quando uma pessoa relata os próprios comportamentos passados (que poderíamos chamar de autorrelato) ou quando relata comportamentos e eventos que presenciou, está emitindo um operante verbal que Skinner denominou tato. Um tato "pode ser definido como um operante verbal no qual uma resposta de uma dada forma é evocada (ou pelo menos fortalecida) por um objeto ou evento particular ou por uma propriedade de um objeto ou evento" (Skinner, 1957, pp. 81-82).

Skinner frequentemente contrapõe o tato a outro operante verbal, o mando, que é definido como "um operante verbal no qual uma resposta é reforçada por uma consequência característica e está, portanto, sob controle funcional de condições relevantes de privação ou estimulação aversiva" (Skinner, 1957, pp. 35-36). O importante no mando, portanto, é a relação entre a resposta e uma consequência específica. No tato, ao contrário, o importante é a relação com o estímulo discriminativo antecedente, o que é "nomeado", "descrito" ou "relatado" no tato.

Para que o controle do estímulo discriminativo antecedente sobre o tato seja acurado, é fundamental uma história de reforço generalizado para o tato. $\mathrm{O}$ reforço generalizado seria imprescindível para desprender o tato dos "interesses pessoais" do falante, fortalecendo a relação com os estímulos discriminativos. Skinner afirma, usando a linguagem comum, que o mando "beneficia o falante" e o tato "beneficia o ouvinte". O mando beneficia o falante na medida em que resulta em alguma consequência específica que é reforçadora para o falante ${ }^{7}$,

\footnotetext{
7 A questão é bem mais complexa do que poderia ser analisado neste texto. Um mando pode ocorrer e não ser reforçado. Por exemplo, eu peço um copo de água e o ouvinte diz para eu mesmo ir pegar. Pedir o copo de água não deixa de ser um mando, porque é um operante que foi estabelecido por uma história de reforço com reforçadores específicos, isto é, muitos pedidos anteriores foram atendidos. O reforço provavelmente terá sido intermitente e sob controle de estímulos, na medida em que mandos têm maior probabilidade de ser atendidos por algumas pessoas do que por outras, em algumas circunstâncias do que em outras, etc.
}

enquanto o tato beneficia o ouvinte na medida em que pode "informar" a ele sobre algo do ambiente ao qual o ouvinte pode não ter acesso. Skinner aponta que "quando a correspondência com uma situação estimuladora é mantida com exatidão, quando as inferências do ouvinte sobre a situação são mais fidedignas, nós chamamos a resposta de 'objetiva', 'válida', 'verídica' ou 'correta”. (Skinner, 1957, p. 147). O controle de estímulos, todavia, praticamente nunca é assim perfeito (a ciência seria a atividade em que as descrições dos processos e fenômenos mais se aproximam desta objetividade). Muitas variáveis contribuem para distorcer a correspondência entre o comportamento verbal e a situação estimuladora: variações no grau de alerta do falante; alterações emocionais, mudanças em estados de privação, etc. Particularmente importantes são consequências especiais providas pelos ouvintes.

Temos aqui duas importantes fontes de distorção dos tatos: a intromissão de reforçadores específicos e o reforçamento generalizado contingente a determinadas topografias de comportamento. Entre os reforçadores específicos que levam a distorções no tato estão reforçadores negativos, quando os tatos verídicos têm probabilidade de serem punidos. No primeiro caso, de intromissão de reforçadores específicos, temos variáveis características do mando se combinando com as que controlam o tato. Uma confissão de um suposto crime, por exemplo, será um tato verídico se houver correspondência acurada com o estímulo discriminativo, ou seja, se a confissão corresponder aos fatos envolvidos no crime. Mas se a confissão é obtida em situações muito aversivas envolvendo, por exemplo, tortura explícita ou muita pressão, o comportamento verbal pode deixar de ser correspondente aos "fatos" e, deste modo, muitos suspeitos confessam crimes que não cometeram ou incriminam inocentes como fuga da situação de interrogatório, ou seja, sob controle de um reforçador negativo específico: o encerramento da tortura ou da pressão. A confissão nestes casos, apesar da aparente forma de tato, teria função de mando, sob controle de uma condição motivacional resultante de estimulação aversiva, sendo negativamente reforçada pelo fim do interrogatório e da tortura. 
Como exemplo do segundo caso, reforçamento generalizado contingente a determinadas topografias de resposta verbal, temos o falante que diz o que sua audiência "quer ouvir", ou o que provoca aprovação e admiração da audiência, sob controle de reforçadores generalizados como atenção, aprovação e admiração. Os "fatos" são distorcidos ou, em muitos casos, totalmente inventados. $\mathrm{O}$ exemplo típico é o pescador que exagera o tamanho do peixe que pescou (ou exibe peixes comprados no mercado como prova de seu sucesso em uma pescaria). Neste sentido, podemos nos perguntar se Tajômaru estaria sendo preciso quando relata 23 cruzamentos de espada em sua luta contra o samurai, ou se não estaria aumentando muito o "tamanho do seu peixe".

Para concluir este ponto, podemos dizer que o reforçamento generalizado garante a precisão do controle discriminativo nos tatos. Diversas variáveis podem solapar esta precisão e resultar em tatos distorcidos ou totalmente falsos. Entre estas estão os "interesses" do falante, ou seja, reforçadores específicos que podem advir do relato ou reforçadores generalizados especiais que podem ser contingentes a determinadas topografias de relato (cf., Ribeiro, 1989). Ou seja, relatos, e especialmente os autorrelatos, estão sujeitos a reforço diferencial pelo conteúdo ou topografia, que pode solapar a correspondência com os acontecimentos ou comportamentos que são relatados.

Voltando agora aos depoimentos dos personagens de Rashômon, estes seriam tatos ${ }^{9}$ sob controle

8 Não tenho conhecimento suficiente do assunto, mas um conhecedor de cultura japonesa me garantiu que é virtualmente impossível 20 cruzamentos de espada na esgrima japonesa, em que geralmente bastariam poucos golpes para a decisão da luta. Se for este o caso, temos uma "história de pescador" em que ou o tamanho do peixe teria sido muito exagerado ou até mesmo o peixe de enorme tamanho teria sido totalmente inventado, pois se o depoimento do morto ou o de sua esposa tiverem sido acurados, a luta nem teria ocorrido.

9 Os auto-relatos dos personagens de Rashômon são tatos muito complexos que estão sob controle discriminativo de sequências de acontecimentos que envolvem ações do próprio depoente e de outras pessoas. Nestes casos, os tatos são geralmente combinados com outras categorias de operantes verbais, como intraverbais e autoclíticos, mas para simplificar a questão vamos considerar que a descrição de um dos acontecimentos que os personagens presenciaram ou dos quais participaram, ou pelo menos têm topografia de tatos, na medida em que "descrevem" o que teria ocorrido. Estes supostos tatos são contraditórios entre si e, portanto, não poderiam ser todos eles verídicos. Talvez um dos depoentes tenha dito a verdade e, neste caso, todas as discrepâncias nos outros depoimentos seriam mentiras, exageros, ou erros devidos a falhas de observação ou distorções de memória. Ou, talvez mais provável, todos os depoentes tenham contado mentiras e/ou tenham lembrado os eventos de forma distorcida. As contradições tornam todos os depoimentos suspeitos e esta suspeição é acentuada porque todos os personagens têm interesses especiais no caso.

No conto de Akutagawa, as contradições são entre os depoimentos do bandido, da mulher e do marido. Não é lançada suspeição sobre o relato do lenhador, que teria apenas encontrado o corpo. $\mathrm{O}$ filme, todavia, acrescenta mais um depoimento suspeito, o do lenhador. Quando ficam sabendo que ele também tem um interesse envolvido, tem algo a esconder, pois foi quem roubou o punhal, o padre e o plebeu passam a duvidar também do depoimento do lenhador (e o lenhador torna-se suspeito também para o espectador do filme).

Ficamos assim com quatro depoimentos em que cada um tem interesses que podem levar à mentira ou exageros. $\mathrm{O}$ bandido já está preso e sabe que vai ser condenado à morte. Ele mostra ter ciência de que negar o crime só poderia piorar a sua situação, pois ele poderia ser torturado para confessar. Podemos considerar como fora de dúvida que ele tenha violado a mulher, pois todos os depoimentos estão de acordo neste ponto (no entanto, dada a inconfiabilidade de todos os testemunhos, isto poderia não ser uma garantia absoluta). Talvez nem tenha sido ele o autor da morte, talvez a confissão seja meramente um comportamento reforçado negativamente ou então um comportamento governado por alguma regra do tipo: "se for apanhado pela polícia é melhor confessar o que eles querem,

acontecimento seria um tato sob controle discriminativo da sequência de acontecimentos que ocorreu. Esta simplificação é válida na medida em que estamos interessados na "veracidade" dos depoimentos, que depende de condições que asseguram o controle discriminativo sobre os tatos. 
para não ser torturado". Seja ele o autor da morte ou não, ele parece empenhado em exagerar os seus feitos e negar qualquer conduta vergonhosa. Ele começa não admitindo ter caído do cavalo (no filme), contando a muito improvável história de ter bebido de uma fonte envenenada. Ele admite ter possuído a mulher, mas (no filme) insinua que seduziu a mulher e não propriamente a estuprou. Quer tenha matado o samurai ou não, ele constrói uma narrativa honrada e gloriosa para o feito. O espectador do filme tem motivos para duvidar de quase tudo o que Tajômaru disse. Pode-se supor que ele tenha dito o que "pensa que sua audiência gostaria de ouvir". Um exemplo seria o caráter heroico da luta com o samurai. Duas testemunhas, a mulher e o samurai, negam que tenha havido tal luta, e a única testemunha que corrobora a existência de uma luta afirma que os dois lutadores se comportaram como covardes e teriam mostrado uma inabilidade que beirava o ridículo.

O detalhe do depoimento do bandido que parece ter maior credibilidade é a afirmação de que não roubou o punhal. Ele afirma a respeito disso (no filme) que deixar o punhal foi o seu maior erro, e Tajômaru não parece o tipo de indivíduo inclinado a admitir que cometeu erros. Como ele já tinha admitido vários crimes, não tinha "nada a ganhar" negando o roubo do punhal, ou seja, não havia um reforço específico para negar, de modo que podemos considerar provável que ele tenha dito a verdade neste ponto. Este único detalhe confiável do depoimento do bandido é essencial para a conclusão do filme: o punhal ficou lá na cena do crime, cravado no chão ou no peito do samurai. Se não estava lá quando a polícia chegou, só poderia ter sido levado por alguma outra pessoa, que teria que ser a mulher ou o lenhador.

Ao analisar o depoimento da mulher não podemos esquecer que ela foi estuprada pelo bandido em presença do marido. O marido teria sido também responsável, pela imprudência de abandona-la sozinha em um local ermo em uma região infestada de bandidos, e por ter cedido à cobiça e se deixado dominar e amarrar por Tajômaru. Mas ao afirmar que o samurai a teria olhado com desprezo e ódio, ela indica que o marido a teria considerado desonrada por ter sido violada e talvez até mesmo culpada por isso. A mulher tinha o temperamen- to forte como qualquer homem, segundo o depoimento da sua mãe, e o bandido confirma isto ao descrever como foi perigoso o ataque dela e como ele precisou de muita habilidade para domina-la. Mas no depoimento ela se apresenta como frágil, principalmente no filme, em que ela apenas sugere a possibilidade de ter matado o marido.

Quanto ao samurai, com base no depoimento dos demais personagens, principalmente do bandido e do lenhador, podemos concluir que seu comportamento foi totalmente contrário ao Bushidô, o código de honra dos samurais. Ele deixou-se levar pela cobiça, foi dominado e amarrado pelo bandido, abandonou sua esposa sozinha à beira da estrada e assistiu impotente ao seu estupro, e tanto o bandido quanto o lenhador afirmam que ele foi derrotado em uma luta justa. O lenhador acrescenta ainda detalhes de grande covardia no comportamento do samurai. Mesmo morto, o samurai ainda estaria sujeito a uma forte punição na cultura japonesa: a desonra em virtude de seu comportamento vergonhoso. Isto tem que ser visto, obviamente, como licença poética: mortos não depõem, não se comportam e, portanto, não estão sujeitos a reforço ou punição. Mas se aceitarmos a licença poética, um depoimento do morto seria também comportamento verbal, sujeito às consequências reforçadoras ou punitivas advindas da reação da audiência. Assim, a suposição dos interlocutores no Portal Rashômon, de que mortos não mentem, não se sustentaria: o samurai, mesmo morto, é provavelmente o que tem mais a ganhar ou perder dependendo de como a história de sua morte será contada. Ao afirmar que se suicidou, o samurai busca recuperar sua honra, pelo menos na morte.

Quanto ao lenhador, já vimos que seu depoimento também está contaminado porque ele também tem algo a esconder. $\mathrm{O}$ fato de ter roubado o punhal coloca todo o seu testemunho como suspeito.

\section{Conclusão}

Os psicólogos do desenvolvimento têm mostrado que crianças começam cedo a mentir quando fazem alguma coisa não permitida. No "Paradigma da Resistência à Tentação", o experimentador diz a uma criança que não é permitido fazer alguma coi- 
sa (como tocar um objeto, por exemplo) e depois ausenta-se por algum tempo. Ao voltar, pergunta se a criança fez o que não era permitido. Os estudos têm mostrado que uma alta proporção das crianças faz a ação proibida e que destas, a maioria nega ter praticado esta ação (Lewis, Stanger \& Sullivan, 1989; Talwar \& Lee, 2008). Estes estudos descrevem o comportamento de grupos de crianças, enquanto estudos de análise do comportamento focalizam comportamento de crianças ou adultos individuais e mostram que a mentira para encobrir erros ou ações não permitidas é relativamente comum (Alves, 2018; Cortez et al., 2014; 2017; Cortez, de Rose \& Montagnoli, 2013; Domeniconi et al., 2014). Nos depoimentos de Rashômon, conto e filme, todos os autorrelatos são contaminados pelos interesses dos depoentes em produzir reforçadores positivos específicos e em se esquivar de estímulos aversivos, principalmente pela negação de condutas puníveis.

A linguagem, ou mais precisamente, o comportamento verbal não é um instrumento para expressão da verdade. Como qualquer comportamento operante, o comportamento verbal é modelado e mantido por reforçamento positivo e negativo (Skinner, 1957; ver também Bandini \& de Rose, 2006; de Rose, 1997). Na medida em que o reforçamento generalizado possibilita o estabelecimento de tatos sob controle preciso de estímulos ambientais como objetos, ações ou propriedades de objetos e ações, o ouvinte pode ser "beneficiado" por tatos verídicos. No entanto, como observa Skinner, as práticas de reforçamento de tatos pela comunidade verbal não conseguem suprimir totalmente a influência de interesses do falante. Isto é ainda mais provável no que tange a autorrelatos, pois neste caso as respostas verbais não são controladas somente pela correspondência com o estímulo discriminativo. Há interferência das contingências sociais a que está sujeito o próprio comportamento relatado. Assim, quando alguém relata ter cometido um erro, praticado uma ação proibida ou cometido um crime, a probabilidade de que o comportamento verbal do falante seja reforçado por sua veracidade é muito menor do que a probabilidade de punição pelo crime ou erro relatado (cf. Cortez et al., 2014; Domeniconi et al., 2014). De modo análogo, quando alguém relata ter praticado alguma ação admirá- vel ou heroica, a probabilidade de reforço por parte da audiência pode ser influenciada mais pela qualidade da resposta relatada do que pela veracidade do relato.

Para reforçar o autorrelato de um indivíduo com base na correspondência e não no conteúdo, em casos em que a audiência não presenciou o acontecimento, seria necessário cotejar o relato com um testemunho confiável. Rashômon sugere que, em muitos casos, ou quiçá todos os casos, não há testemunhos confiáveis. $\mathrm{O}$ filme tem sido tomado como apoio para concepções da realidade como uma construção subjetiva. Muitos analistas interpretam os relatos não como mentiras, mas como diferentes percepções dos atores envolvidos num evento. Roth e Mehta (2002), por exemplo, argumentam que cada personagem expressa a "sua" verdade e que o fato de que cada um dos três mais diretamente envolvidos afirmar ter sido o autor da morte indica que eles não estariam mentindo.

De fato, temos em Rashômon uma inversão da situação típica das histórias de detetive, nas quais os personagens geralmente negam terem sido autores do crime e eventualmente o detetive descobre e revela a verdade (e nas histórias típicas de detetive, praticamente todos os personagens mentem, mesmo os "inocentes", porque têm alguma coisa a esconder). Assim, autores inclinados a uma visão construcionista tendem a especular que não haveria "uma verdade" em Rashômon. A pesquisa psicológica recente mostra que é de fato possível que cada personagem estivesse acreditando na sua versão e que as discrepâncias nos relatos poderiam se dever a falsas memórias e não a mentiras (cf. Aggio, Pedrosa \& de Rose, 2017; Loftus 1975; Stein, 2010). No entanto, como vimos, ao contrário das histórias típicas de detetive, em Rashômon os personagens têm a ganhar, não a perder, por se afirmarem autores da morte. E, como sugere Loftus em sua pesquisa e em seu Ted Talk, nada impede que uma mentira se torne também uma falsa memória: o próprio indivíduo que conta a mentira pode passar a acreditar nela, e na história de Rashômon os personagens têm motivos não apenas para mentir como também para acreditar em suas mentiras.

Certamente o filme não nega a existência de uma verdade sobre os fatos, ou pelo menos sobre alguns deles. Alguém cravou uma arma no peito do 
samurai, causando a sua morte. Não é possível saber quem fez isto apenas com base nos depoimentos e no Japão medieval não havia outros recursos para se descobrir o autor da morte. Talvez nos dias de hoje, com recurso a impressões digitais, análise de DNA, etc., seria possível determinar com segurança quem foi o autor. Outras dúvidas poderiam persistir, principalmente sobre as motivações dos personagens, mas isto seria assunto para outro artigo.

\section{Referências}

Aggio, N. M., Pedrosa, S. C. D., \& de Rose, J. C. (2017). Falsas memórias na perspectiva da análise do comportamento: Uma análise da literatura. Acta Comportamentalia, 25, 379-393.

Alves, C. (2018). Correspondência fazer-dizer em adultos: O controle pela audiência em um jogo virtual. Tese de doutorado, Programa de PósGraduação em Psicologia, Universidade Federal de São Carlos.

Anderer, P. (2016). Kurosawa's Rashomon: A vanished city, a lost brother, and the voice inside his iconic films. New York: Pegasus.

Arantes, A. K. A., \& de Rose, J. C. (2009). Controle de estímulos, modelagem do comportamento verbal e correspondência no "Otelo" de Shakespeare. Revista Brasileira de Terapia Comportamental e Cognitiva, 11, 61-76.

Bastos, R., \& Medeiros, C.A., (2016). Correspondência verbal em um jogo de cartas com crianças. Acta Comportamentalia, 24, 15-24.

Bandini, C. S. M., \& de Rose, J. C. (2006). A abordagem behaviorista do comportamento novo. Santo André: Esetec.

Cortez, M. D., de Rose, J. C., \& Miguel, C. F. (2014). The role of correspondence training on children's self-report accuracy across tasks. The Psychological Record, 64, 393-402. Doi: 10.1007/ s40732-014-0061-8

Cortez, M. D., de Rose, J. C., \& Montagnoli, T. A. (2013). Treino e manutenção de correspondência em autorrelatos de crianças com e sem história de fracasso escolar. Acta Comportamentalia, $21,139-157$.

Cortez, M. D., Miguel, C. F., \& de Rose, J. C. (2017). Efeitos de diferentes tipos de treino de correspondência na manutenção de autorrelatos correspondentes de crianças. Acta Comportamentalia, 25, 511-517.

Cotler, M. P. (2013). Bioethics consultation: The Rashomon effect. Medicine and Law, 32, 205212.

DePaulo, B. M., \& Kashy, D. A. (1998). Everyday lies in close and casual relationships. Journal of Personality and Social Psychology, 74, 63-79. Doi: 10.1037/0022-3514.74.1.63

De Rose, J. C. (1997). O relato verbal segundo a perspectiva da análise do comportamento: Contribuições conceituais e experimentais. Em: R. A. Banaco (Org), Sobre comportamento e Cognição, Vol. 1. Aspectos teóricos, metodológicos e de formação em análise do comportamento e terapia cognitiva. São Paulo: Arbytes.

Domeniconi, C., de Rose, J. C., \& Perez, W. F. (2014). Effects of correspondence training on self-reports of errors during a reading task. The Psychological Record, 64, 381-391. Doi: 10.1007/ s40732-014-0009-Z

Feldman, R. S., Forrest, J. A., \& Happ, B. R. (2002). Self-presentation and verbal deception: Do self-presenters lie more? Basic and Applied Social Psychology, 24, 163-170. Doi: 10.1207/ S15324834BASP2402_8

Glenn, S. S. (1983). Maladaptive functional relations in client verbal behavior. The Behavior Analyst, 6, 47-56. Doi: 10.1007/BF03391873

Heider, K. G. (1988). The Rashomon effect: When ethnographers disagree. American Anthropologist, 90, 73-81.

Lanza, R. P., Starr, J., \& Skinner, B. F. (1982). "Lying” in the pigeon. Journal of the Experimental Analysis of Behavior, 38, 201-203. Doi: 10.1901/ jeab.1982.38-201

Lewis, M., Stanger, C., \& Sullivan, M. V. (1989). Deception in 3-year-olds. Developmental Psychology, 25, 439-443. Doi: 10.1037/00121649.25.3.439

Loftus, E. F. (1975). Leading questions and the eyewitness report. Cognitive Psychology, 7, 550572. Doi: 10.1016/0010-0285(75)90023-7

Medeiros, C. A., Oliveira, J. A., \& Silva, C. O. (2013). Correspondência verbal em situação lúdica: Efeitos da probabilidade de checagem. Fragmentos de Cultura, 23, 563-578. 
Newton, P., Reddy, V., \& Bull, R. (2000). Children's everyday deception and performance on false-belief tasks. British Journal of Developmental Psychology, 18, 297-317. Doi: 10.1348/026151000165706

Oliveira, M. A., Cortez, M. D., \& de Rose, J. C. (2016). Efeitos do contexto de grupo no autorrelato de crianças sobre seus desempenhos em um jogo computadorizado. Perspectivas em Análise do Comportamento, 7, 70-85.

Ribeiro, A. F. (1989). Correspondence in children's self-report: tacting and manding aspects. Journal of the Experimental Analysis of Behavior, 51, 361-367. Doi: 10.1901/jeab.1989.51-361

Roth, W. S., \& Mehta, J. D. (2002). The Rashomon effect: Combining positivist and interpretivist approaches in the analysis of contested effects. Sociological Methods and Research, 31, 131-173. Doi: 10.1177/004912402237292

Skinner, B. F. (1957). Verbal behavior. Englewood Cliffs, NJ: Prentice Hall.

Skinner, B. F. (1971). Beyond freedom and dignity. Indianapolis: Hackett.

Stein, L. M. (2010). Falsas memórias: Fundamentos científicos e suas aplicações clínicas e jurídicas. Porto Alegre: Artes Médicas.

Talwar, V. \& Lee, K. (2008). Social and cognitive correlates of children's lying behavior. Child Development, 79, 866-881. Doi: 10.1111/j.1467$-8624.2008 .01164 . \mathrm{x}$

Informações do Artigo

Histórico do artigo:

Submetido em: 29/03/2018

Aceito em: 26/06/2019 